\title{
National scientific capabilities and technological performance: An exploration of emerging industrial relevant research domains
}

\section{Bart Van Looy**, Koenraad Debackere**, Julie Callaert*, Robert Tijssen", Thed van Leeuwen ${ }^{\#}$}

\author{
*Research Division INCENTIM, \\ Faculty of Economics and Applied Economics, K.U.Leuven, Belgium \\ **and Steunpunt O\&O Statistieken \\ K.U.Leuven \\ Belgium \\ ${ }^{\#}$ CWTS Leiden, the Netherlands
}

Paper presented at the S\&T Indicators Conference

September 2004 - Leiden, the Netherlands

All correspondence regarding this paper can be addressed to:

Bart.vanlooy@econ.kuleuven.ac.be

* This paper is based on results from a research project funded by European Commission/DG Research (contract no HPV2-CT2001-00012). 


\begin{abstract}
Today's theories and models on innovation stress the importance of scientific capabilities and science-technology proximity, especially in new emerging fields of economic activity. In this contribution we examine the relationship between national scientific capabilities, the science intensity of technology and technological performance within six promising industrial fields. Our findings reveal that national technological performance is positively associated with scientific capabilities. Countries performing better on a technological level are characterized both by larger numbers of publications and by numbers of involved institutions that exceed average expected values. The latter observation holds for both companies and knowledge generating institutes actively involved in scientific activities. As such, our findings seem to suggest beneficial effects of scientific capabilities shouldered by a multitude of organizations. In addition, higher numbers of patent activity coincide with higher levels of science intensity pointing out the relevance of science 'proximity' when developing technology in newer, emerging fields. Limitations and directions for further research are discussed.
\end{abstract}




\section{Introduction}

Innovation is one of the major drivers behind economical development and as a consequence a primary concern for practitioners, policy makers and researchers alike. In today's theories and models on innovation, the contribution of knowledge is cast in a central role, implying an increased interest in the part that knowledge generating institutes (KGIs) such as universities and public research centres - can play within today's innovation systems. Combining this with the obvious role of business actors and the important function of governments in stimulating and regulating innovation, a multiple-actor perspective emerges in which interactions figures prominently. Innovation scholars have captured this multitude of actors and interactions in a strand of theories and models that increasingly move away from linear assumptions. Network dynamics, interactions and circularity have become core elements in today's innovation studies, as can be witnessed in the work on scientific networks (Pavitt, 1997; Steinmuller, 1994; David et al., 1997); the vision on industry, academia and government interactions, as encompassed by the 'Triple Helix' model (Leydesdorff \& Etzkowitz, 1996; Etzkowitz \& Leydesdorff, 1998) and the concept of national or regional 'innovation system' (Nelson 1993; OECD 1999). Theories and models on regional clustering and innovation networks further illustrate how cooperation and interaction are recognized as important ingredients for the development of the innovative potential of regions or nations (Porter, 1995; Varga, 1998). The importance of the regional presence of knowledge generating, scientific institutes is a central theme in this work.

Several authors have empirically confirmed the role of scientific centres for regional development. Anselin et al. (1997) provided evidence of local spillovers at the US state and MSA (Metropolitan Statistical Area) level. Blind and Grupp (1999) examined eighteen technology zones in Baden-Würtemberg and Nordrhein-Westfalen, and established a clear link between the presence of public institutions of higher learning and the technology-output in a particular geographical area. More recently, Fischer and Varga (2003) provided evidence on the importance of geographically mediated knowledge spillovers from university research activities to regional knowledge production in high-technology industries in Austria. They showed geographically mediated university spillovers to transcend the spatial scale of political districts and demonstrated a clear distance decay pattern for such spillovers. Niosi and Bas (2001) analyzing Canadian biotech clusters, found universities - along with government laboratories and a few large firms - to attract entry of new firms. Monjon and Waelbroeck (2003) found that spillovers from universities to innovative firms can provide benefits to those firms. They found a differential effect according to the type of innovation that is pursued: incremental innovations benefit most from knowledge spillovers. Highly innovative firms, working at the frontier of academic knowledge, were found to benefit more from collaborative research with foreign universities.

These theoretical and conceptual evolutions, along with the empirical support, highlight the relevance of a set of indicators to allow studying and analyzing the relationship between the presence of scientific actors and capabilities on the one hand and technological performance on the other hand. Bibliometric indicators have, since a few decades, been widely adopted for benchmarking and assessing science and technology (see for instance the European Reports on Science and Technology Indicators and the US NSF Reports on Science and Engineering Indicators). Publication related indicators have served mostly in mapping 
scientific efforts, while patent related indicators are applied for assessing technological activity. Increasingly, quantitative indicators are designed to depict relatedness and interdependencies between the science and technology sphere, thereby grasping more completely the concept of what has nowadays become referred to as 'innovation system' (Schmoch, 1997; Tijssen, 2001). Such indicators include public-private coauthored publications and co-owned patents; as well as citations between both activity spheres, mostly scientific references in patents (Narin et al. 1997; Verbeek et al., 2002; Tijssen et al. 2000).

At the same time, empirical studies including indicators pertaining to scientific capabilities, technological performance and their relatedness on the level of national innovation systems seem scarce. Van Looy et al., (2003) investigated the impact of sciencetechnology relatedness on the effectiveness of technology development on a country level. In science intensive fields, they found a positive relation between the science intensity of patents (measured by the amount of non-patent references) and technological productivity. Their findings suggest the relevance of fostering relations between knowledge generating actors and technology producers, especially in science intensive fields. It can be observed that in this analysis, indicators pertaining to the scientific capabilities of a country have not been taken into account. As such, the observed positive relationships might stem from the presence of scientific capabilities; in this case one would merely be counting 'spill over' effects that could be assessed equally by established bibliometric indicators pertaining to scientific publications. Hence, further analysis - whereby indicators pertaining to scientific capabilities are taken into account - is required for assessing the relevancy of using non patent references as an (additional) indicator to explain differences in technological performance. It is in this area that we want to situate our contribution. The associations between the presence of scientific capabilities and technological productivity will be explored through the following questions:

- To what extent are scientific capabilities positively related to the technological performance of nations?

- Is science-technology relatedness - as measured by the amount of non-patent references - still positively associated with technological performance when scientific capabilities are brought into the equation?

In our analysis, we focus on emerging and knowledge-intensive fields, as the potential role of scientific capabilities for the development of technological activities seems to be most outspoken within such domains (cf. supra). The data pertain to the following emerging 'hot topics', i.e. new emerging domains with considerable levels of industrial relevance:

- Fuel Cells

- Stem Cells

- Conductive Polymers

- Nano-electronics

- Femto-second lasers

- Tissue Engineering/Alzheimer’s Disease

All indicators and concepts are aggregated on a country level, providing a picture of scientific and technological activity that coincides with the level of 'national' innovation systems. The results obtained should hence be interpreted on this level of analysis. In the next section, we will discus the concepts and indicators used in more depth. Equipped with this background, data sources and obtained results will be presented. We conclude this paper by discussing the results and their implications. 


\section{Constructs \& Indicators}

\section{Scientific Capabilities}

The total amount of publications in a specific domain for a given country is used as an indicator of scientific performance. Relevant publications were retrieved from the Thomson Scientific's Science Citation Index ${ }^{\circledR}{ }^{1}$ based on validated search keys for each of the domains included. In a next step, all retrieved publications were allocated to countries based on the 'nationality' of the organizational affiliation of the authors. In the case of internationally coauthored papers, full counts were applied to acknowledge all countries involved. In addition, the number of research institutes and the number of companies associated with these publications were included as explanatory variables. The publications to which a company is associated are mostly company-university co-authored papers. As such, companyinvolvement in publications could also be considered as signaling science-technology interactions (e.g. Tijssen, 2004).

\section{Science-Technology Relatedness}

An additional indicator of science-technology relatedness that we introduced in the analysis pertains to the amount of non-patent references found in patents. These non patent or 'other' references are included on the front page of patents, and signal the presence of relevant (non patent) prior art that qualifies and contextualizes the novelty and inventiveness of the patent claims and their applicability. Hence, any interpretation of non-patent references should take into account the specific context of use, i.e. the patent application and granting process (Michel \& Bettels, 2001; Harhoff et al, 2003; Meyer et al., 2003; Van Looy et al., 2003). An in depth analysis of the use of non-patent references in the invention and application process reveals that they should not be considered as signaling a direct influence or causation between the two documents, i.e. citing patent and cited article (Tijssen, 2002; Meyer, 2000a, 2000b). Rather, the presence of scientific research in the 'prior art' description of a patented invention can be understood as an indicator of the 'distance' between scientific findings on the one hand and technology development on the other hand. As references in patents are a reflection of prior art, more references towards science fields signal more relevant prior art derived from scientific sources. This does not equal a uni-directional, influencing or contributing, link from the cited paper towards the citing patent. However, it should be clear that if more scientific references are considered relevant for assessing and contextualizing the claims made within the patent, then the technology is situated closer to scientific activity (Van Looy et al. Forthcoming). So without postulating a direct link of causation or an immediate interaction, the average amount of non-patent references found in patents are considered here as indicative of a certain level of relatedness or 'proximity' between scientific and technological activities.

For each domain, year and country, the total number of non-patent references (NPRs) was calculated for all the patents implied. In a next step, the average number of NPRs was

\footnotetext{
${ }^{1}$ The data were extracted from the CWTS bibliometric database, which is based on the Thomson Scientific Citation Indices (CD ROM version) and operated by CWTS under a licence agreement with Thomson Scientific.
} 
calculated by domain, year and country. Averages (per patent) were used instead of absolute numbers, because absolute number of non patent references almost completely coincides with total amount of patents $(\mathrm{r}=0,93, \mathrm{p}<0,001)$.

\section{Technological Performance}

Technological performance is measured by the number of patents produced in a given country for each year in the time period 1997-2001. USPTO patents were used, as these contain significantly more NPRs than EPO patents. Both variables were logarithmically transformed in order to obtain a normal distribution ${ }^{2}$. Note that only those countries are analyzed where patenting activity is observed in the considered timeframe. Patent output is used as the dependent variable, and considered as an indication of the technological performance of a given country in a given year. As such, we will examine whether and to what extent differences in scientific activities as well as in S-T relatedness coincide with the differences in the amount of patent activity taking place.

Finally, two control variables were included. First of all, the country size in terms of population size was taken into account. Second, the year in which patent activity took place (application date) was introduced. This is of special importance, because granted patents were used for the time period 1997 - 2001. Given the time period between applying and granting patents, the data extracted in 2003 show a decreasing trend - in terms of absolute numbers from 2000 onwards. This becomes clear in table 1. Tables 2 and 3 provide an insight in the distribution of data by field and by country.

Insert Table 1 - Distribution of observations by year

Insert Table 2 - Distribution of observations by domain/hot topic

Insert Table 3 - Distribution of observations by country

\section{Analysis: Descriptive statistics and correlations}

Before looking at the specific analyses conducted to address the aforementioned questions, some descriptive statistics will be provided. Table 4 gives a summary overview of the different variables, broken down by domain. The reported figures relate to the observed values, averaged over the countries and years that are included in the analysis. As table 4 makes clear, both patent and publication outputs vary by domain. With regard to patents, higher figures are observed for Femto-second Lasers, Nanoelectronics and also Fuel Cells. For publications, average figures are highest for Nano-electronics and especially for Stem Cells. A similar pattern can be noticed for the number of publishing knowledge generating institutes (KGIs). The number of companies actively involved in the production of scientific papers is considerably lower, but note a relatively high average number of publishing companies in the field of Stem Cells. The following countries are responsible for these higher

\footnotetext{
${ }^{2}$ Such a transformation has also been applied to the scientific and S-T variables, for the same reason.
} 
levels of both number of publications and number of publishing KGIs: USA, Japan, France, Germany and to a lesser extent the United Kingdom. Finally, the average amount of NPRs is highest in pharmaceutical/biotechnology related fields (Alzheimer/Tissue Engineering and Stem Cells).

Insert Table 4 - Average of variables by domain (over year and country)

Table 5 reports on the correlations between the different variables that are included in the analysis. First, and this should come as no surprise, population significantly correlates with all other variables - except with the average amount of NPRs. This observation confirms the relevance of including population as a control variable. Second, high correlations are found between the indicators reflecting actors and output of scientific activity: total amount of publications, number of knowledge generating institutes associated with these publications and finally the number of companies associated with these publications. The multicollinearity between these variables inspired us to apply ANCOVA and regression models with residuals values for number of publishing KGIs and number of publishing companies. Finally, significant but moderate correlations are observed between the average amount of NPRs and the number of publishing KGIs.

Insert Table 5 - Correlations between key variables (All fields)

\section{Addressing the research questions: does technological performance - on a national level - relate to scientific performance and/or science-technology relatedness?}

The central research questions pertain to the relationship between patenting performance on the one hand, and levels of scientific activity (number of publications) as well as science-technology relatedness on the other hand. Science-technology relatedness was measured by: the number of companies actively contributing to scientific activity (publications authored or co-authored by companies); the number of actively contributing knowledge generating institutes (universities or public research organizations) within a certain subfield as well as the (average) amount of non patent references. In addition, domain differences, country sizes and the impact of the time period considered (year) were taken into account when analyzing the relationship with technological activity.

As stated earlier, a multicollinearity issue arises due to the extremely high correlations between three of the independent variables: the amount of publications, the amount of publishing companies and the amount of publishing KGIs $(r=+/-0,90)$. This implies that the robustness of the findings obtained for these variables can be questioned, because their effects are to a large extent interchangeable. In order to asses their distinctive effects; two intermediate regressions were performed with the number of publications acting as an independent variable. The number of publishing companies and the number of KGIs were treated respectively as dependent variables. In a next step, the residual values were calculated both for number of publishing companies and for number of publishing KGIs. In doing so, the influence of the total amount of publications - as reflected in the regression equation - is removed from the amount of contributing actors. As a consequence, the correlation between the number of publications and the (standardized) residual values for number of companies and number of KGIs equals zero. 
In a next step, an Ancova analysis (Analysis of Co-Variance) was performed with patent activity as dependent variable and domain and year as fixed factors (categorical data). Covariates are: the amount of publications, the residual values obtained for the number of KGIs and Companies involved in these publications, the average number of NPRs and finally population figures. Analyses are performed on the logarithmically transformed variables. Table 6 summarizes the results obtained.

\section{Insert Table 6 - Results of ANCOVA}

As an inspection of Table 6 reveals, several variables significantly relate to patenting performance. A significant relation, which can be assumed to be positive, was found with population size. The appearance of significant domain effects can be considered in line with the average patent volumes as reported in Table 4. More interesting from the perspective of the research questions posed, are the results obtained for the scientific and 'sciencetechnology relatedness' indicators. Both the number of publications and the average amount of NPRs (used as an indicator of science-technology relatedness) are significantly related to technological performance. At the same time, it can be noted that the variables pertaining to the number of actors (KGIs and companies) still relate significantly to technological performance, despite the elimination of shared variance with the total amount of publications. Stated otherwise, the residual values of both the number of publishing companies and the number of publishing KGIs significantly contribute to the variance observed in terms of patent activity, independent from the total amount of publications. Finally, one notes a significant year effect. Considering table 1, this effect can be assumed to be negative. At the same time Domain*Year interaction effects are not present; implying that the same trend is equally manifest in all domains under study. The hypothesis that the observed year effects are due to the time lag inherent in the granting process of patents - resulting in a significant decline of patent activity after 2000 - is confirmed when performing a similar analysis for the time period 1997-1999 only. The significance of the relationships examined, mirrors the findings of Table 6 except for year, which is no longer significant.

Finally, the regression analysis, complementing the ANCOVA results of Table 6, provides a systematic view on the signs of the observed relationships. Dummy variables were introduced for the different domains, with FemtoSecond Lasers acting as reference point. Table 7 indicates positive beta values for the key variables under study: scientific activity and average amount of NPRs. In addition, one observes positive values for both the number of companies and the number of KGIs involved in scientific activity.

Insert Table 7 - Regression Results

\section{Discussion and directions for further research}

As these analysis are of an exploratory nature, additional analysis and verification efforts are advisable (see below) to confirm the robustness of the results obtained. At the same time, the findings presented here are more than interesting and promising.

Firstly, the overall explained variance is considerable: the variables introduced in the model explain over $50 \%$ of the variance observed in technological activity. 
Secondly, some first intermediate conclusions can be derived, relating to the relevance of the indicators explored and developed. Both the indicators for scientific activity and for science-technology relatedness appear to significantly coincide with variation that is observed in terms of patent activity. Stated differently, countries performing better on a technological level - as measured by the amount of patenting activity - are characterized both by larger numbers of publications and by numbers of involved institutions that exceed average expected $^{3}$ values. The latter observation holds for both companies and knowledge generating institutes actively involved in scientific activities. As such, our findings seem to suggest beneficial effects of scientific capabilities shouldered by a multitude of organizations. In addition, higher numbers of patent activity coincide with more NPRs, pointing out the relevance of science 'proximity' when developing technology in newer, emerging fields.

The positive statistical relationship with scientific research activity that is carried out by companies may come as a surprise, considering the general trend in the business sector to reduce the engagement in more exploratory ('basic') scientific research. However, this change of orientation does not necessarily affect the R\&D strategies of the technology companies that are leading technology developers in the high-tech science-based sectors, who still continue to conduct a minimum level of in-house research and who, more importantly, have increased their outsourcing of basic research to the public sector research organizations, public-private joint research ventures or technology development centres. Each of the hot topics dealt with in this analysis are exemplars of knowledge domains and fledging industrial sectors, where industry has to be active at the cutting edge of both basic and applied science in order to reap the 'first mover' benefits in competitive global markets (either in terms of acquiring patents, selling licenses, or launching innovative products and processes).

It goes without saying that these findings need to be further corroborated by efforts geared towards confirming and further developing the insights obtained so far. Extending the analyses towards other sub-domains and hot topics seems relevant and may allow further documentation of technology life cycle dynamics and their impact on the relationships found. The authors are currently examining the possibilities to extend the findings by introducing longer time frames: relating scientific, technological activities and their interactions over time will allow assessing more precisely the (assumed reciprocal) influence of the different activity realms and their effects on performance as well as delineate more precisely the moderating impact of technological life cycle stages.

\footnotetext{
${ }^{3}$ Expected values based on publication volume
} 
Table 1 - Distribution of observations by year

(number of countries*fields for which observations are available)

\begin{tabular}{l|ccc}
\hline & Frequency & Percent & Cumulative Percent \\
\hline 1997 & 72 & 29,9 & 29,9 \\
1998 & 68 & 28,2 & 58,1 \\
1999 & 65 & 27,0 & 85,1 \\
2000 & 30 & 12,4 & 97,5 \\
2001 & 6 & 2,5 & 100,0 \\
\hline Total & 241 & 100,0 & \\
\hline
\end{tabular}

Table 2 - Distribution of observations by domain/hot topic (Number of years*countries for which observations are available)

\begin{tabular}{l|ccc}
\hline & Frequency & Percent & Cumulative Percent \\
\hline Nano-electronics & 61 & 25,3 & 25,3 \\
Femto-second Lasers & 55 & 22,8 & 48,1 \\
Fuel Cells & 38 & 15,8 & 63,9 \\
Alzheimer & 36 & 14,9 & 78,8 \\
Conducting Polymers & 31 & 12,9 & 91,7 \\
Stem Cells & 20 & 8,3 & 100,0 \\
\hline Total & 241 & 100,0 & \\
\hline
\end{tabular}

Table 3 - Distribution of observations by country (Number of domains*years for which observations are available)

\begin{tabular}{l|ccc}
\hline & Frequency & Percent & Cumulative Percent \\
\hline JAPAN & 26 & 10,8 & 10,8 \\
USA & 26 & 10,8 & 21,6 \\
GERMANY & 21 & 8,7 & 30,3 \\
CANADA & 17 & 7,1 & 37,3 \\
FRANCE & 15 & 6,2 & 43,6 \\
SOUTH KOREA & 15 & 6,2 & 49,8 \\
UK & 15 & 6,2 & 56,0 \\
TAIWAN & 13 & 5,4 & 61,4 \\
ITALY & 12 & 5,0 & 66,4 \\
SWITZERLAND & 12 & 5,0 & 71,4 \\
ISRAEL & 9 & 3,7 & 75,1 \\
DENMARK & 8 & 3,3 & 78,4 \\
NETHERLANDS & 7 & 2,9 & 81,3 \\
AUSTRALIA & 6 & 2,5 & 83,8 \\
FINLAND & 5 & 2,1 & 85,9 \\
BELGIUM & 4 & 1,7 & 87,6 \\
HONG KONG & 3 & 1,2 & 88,8 \\
SINGAPORE & 3 & 1,2 & 90,0 \\
SWEDEN & 3 & 1,2 & 91,3 \\
ALL OTHER & 21 & 8,7 & 100 \\
\hline Total & 241 & 100,0 & \\
\hline
\end{tabular}

Table 4 - Average of variables by domain (over year and country)

\begin{tabular}{l|llllll}
\hline & Alzheimer & $\begin{array}{l}\text { Fuel } \\
\text { Cells }\end{array}$ & $\begin{array}{l}\text { FS } \\
\text { Lasers }\end{array}$ & $\begin{array}{l}\text { Nano- } \\
\text { Electronics }\end{array}$ & $\begin{array}{l}\text { Conductive } \\
\text { Polymers }\end{array}$ & $\begin{array}{l}\text { Stem } \\
\text { Cells }\end{array}$ \\
\hline Patents & 9,97 & 14,53 & 33,51 & 19,90 & 5,87 & 6,45 \\
Publications & 54,33 & 19,45 & 18,98 & 98,28 & 23,10 & 530,70 \\
\# of publishing KGIs & 18,22 & 8,89 & 8,75 & 26,34 & 12,00 & 96,85 \\
\# of publishing Companies & 1,72 & 2,39 & 1,13 & 3,54 & 1,97 & 13,65 \\
Average amount of Non Patent & 14,06 & 1,84 & 2,61 & 2,73 & 3,62 & 14,43 \\
References & & & & & & \\
\hline
\end{tabular}


Table 5 - Correlations between key variables (All fields)

\begin{tabular}{|c|c|c|c|c|c|c|c|}
\hline & & Patents & Publications & $\begin{array}{l}\text { Number of } \\
\text { Publishing } \\
\text { KGI's }\end{array}$ & $\begin{array}{l}\text { Number of } \\
\text { Publishing } \\
\text { Companies }\end{array}$ & Population & $\begin{array}{l}\text { Average } \\
\text { Number of } \\
\text { NPR's }\end{array}$ \\
\hline \multirow[t]{3}{*}{ Patents } & Pearson Correlation & 1 & ,116 & ,199** &, $191^{\star *}$ & ,250** &,- 006 \\
\hline & Sig. (2-tailed) & , & ,072 & ,002 & ,003 & ,000 & ,923 \\
\hline & $\mathrm{N}$ & 241 & 241 & 241 & 241 & 239 & 241 \\
\hline \multirow[t]{3}{*}{ Publications } & Pearson Correlation & ,116 & 1 & ,933** & $877^{* *}$ & ,229** & ,163* \\
\hline & Sig. (2-tailed) & ,072 & &, 000 & ,000 & ,000 & ,011 \\
\hline & $\mathrm{N}$ & 241 & 241 & 241 & 241 & 239 & 241 \\
\hline \multirow{3}{*}{$\begin{array}{l}\text { Number of } \\
\text { Publishing KGI's }\end{array}$} & Pearson Correlation & ,199** & ,933** & 1 & 861 ** &, 276 ** & ,160* \\
\hline & Sig. (2-tailed) &, 002 &, 000 & & ,000 & ,000 & ,013 \\
\hline & $\mathrm{N}$ & & & 241 & 241 & 239 & 241 \\
\hline \multirow{3}{*}{$\begin{array}{l}\text { Number of } \\
\text { Publishing } \\
\text { Companies }\end{array}$} & Pearson Correlation & ,191** & $877^{* *}$ & 861 , ** & 1 &, $262 * \star$ & ,102 \\
\hline & Sig. (2-tailed) &, 003 &, 000 &, 000 & , &, 000 & 116 \\
\hline & $\mathrm{N}$ & 241 & 241 & 241 & 241 & 239 & 241 \\
\hline \multirow[t]{3}{*}{ Population } & Pearson Correlation & ,250** & ,229** &, $276^{* \star}$ &, $262^{* *}$ & 1 & ,080 \\
\hline & Sig. (2-tailed) & ,000 & ,000 & ,000 & ,000 & , & ,218 \\
\hline & $\mathrm{N}$ & 239 & 239 & 239 & 239 & 239 & 239 \\
\hline \multirow{3}{*}{$\begin{array}{l}\text { Average number of } \\
\text { NPR's }\end{array}$} & Pearson Correlation &,- 006 & ,163* &, $160 *$ & ,102 & ,080 & 1 \\
\hline & Sig. (2-tailed) & ,923 & 011 & ,013 & ,116 & ,218 & , \\
\hline & $\mathrm{N}$ & 241 & 241 & 241 & 241 & 239 & 241 \\
\hline
\end{tabular}

Table 6 - Results of ANCOVA

Dependent Variable: Patent Activity; Domain and Year as Fixed Factors; All other variables: Covariates. Number of KGIs/Companies involved in scientific research activity: Residual values (corrected for total amount of publications)

Time Period: 1997 - 2001

\begin{tabular}{|c|c|c|c|c|c|}
\hline Source & $\begin{array}{l}\text { Type III Sum of } \\
\text { Squares }\end{array}$ & $\overline{d f}$ & $\begin{array}{l}\text { Mean } \\
\text { Square }\end{array}$ & $\bar{F}$ & Sig. \\
\hline Corrected Model & 45,260 & 32 & 1,414 & 10,183 & 000 \\
\hline Intercept & 2,095 & 1 & 2,095 & 15,084 & 000 \\
\hline Publications & 6,094 & 1 & 6,094 & 43,873 & 000 \\
\hline Population & 1,256 & 1 & 1,256 & 9,043 & 003 \\
\hline Average Amount of Non Patent References & 1,782 & 1 & 1,782 & 12,829 & 000 \\
\hline $\begin{array}{l}\text { Number of KGIs involved in scientific activity } \\
\text { (Residual Value) }\end{array}$ & 1,393 & 1 & 1,393 & 10,026 & 002 \\
\hline $\begin{array}{l}\text { Number of Companies involved in scientific activity } \\
\text { (Residual Value) }\end{array}$ & 5,588 & 1 & 5,588 & 40,232 & ,000 \\
\hline Domain & 9,012 & 5 & 1,802 & 12,977 & ,000 \\
\hline Year & 5,261 & 4 & 1,315 & 9,470 & ,000 \\
\hline Domain * Year & 2,023 & 18 & ,112 & ,809 & ,688 \\
\hline Error & 28,613 & 206 & ,139 & & \\
\hline Total & 208,541 & 239 & & & \\
\hline Corrected Total & 73,873 & 238 & & & \\
\hline
\end{tabular}

R Squared $=, 613$ (Adjusted R Squared $=, 553$ ) 
Table 7 - Regression Results

Dependent Variable: Patent activity

Number of KGIs/Companies involved in scientific research activity: Residual values (corrected for total amount of publications)

Time Period: 1997 - 2001

\begin{tabular}{l|ccccc}
\hline Variable & $B$ & SE & Beta & $T$ & Sign T \\
\hline (Constant) & 251,037 & 46,944 & & 5,348 &, 000 \\
Stem cells Y/N & $-1,121$ &, 132 &,- 558 & $-8,477$ &, 000 \\
Conductive Polymers Y/N &,- 469 &, 086 &,- 283 & $-5,423$ &, 000 \\
Nano Electronics Y/N &,- 227 &, 088 &,- 176 & $-2,583$ &, 010 \\
Fuel Cells Y/N &,- 217 &, 081 &,- 143 & $-2,667$ &, 008 \\
Alzheimer Y/N &,- 476 &, 090 &,- 307 & $-5,279$ &, 000 \\
Year &,- 126 &, 023 &,- 250 & $-5,369$ &, 000 \\
Amount of Publications &, 351 &, 061 &, 468 & 5,730 &, 000 \\
Average Amount of Non Patent References &, 309 &, 071 &, 237 & 4,366 &, 000 \\
Population &, 197 &, 062 &, 219 & 3,165 &, 002 \\
Number of KGIs involved in scientific activity &, 089 &, 027 &, 164 & 3,344 &, 001 \\
(Residual Value) & & & & & \\
Number of companies involved in scientific activity &, 139 &, 025 &, 254 & 5,554 &, 000 \\
(Residual Value) & & & & & \\
\hline
\end{tabular}




\section{References}

Anselin, L., Varga, A., \& Acs, Z. (1997) "Local geographic spillovers between university research and high technology innovations,” Journal of Urban Economics, 42 (3), pp. 422-448.

Blind, K. \& Grupp, H. (1999), "Interdependencies between the Science and Technology Infrastructure and Innovation Activities in German Regions: Empirical Findings and Policy Consequences”, Research Policy, Vol. 28, No. 5: 451-468.

David, P.A., Foray, D., Steinmueller, W.E. (1997). The research network and the new economics of science: From metaphors to organizational behaviour, in: Gambardella, A., Malerba, F. (Eds.), The Organisation of Innovative Activities in Europe. Cambridge University Press.

Etzkowitz, H., \& Leydesdorff, L. (1998). “The endless transition: A ‘triple helix’ of university-industry-government relations.” Minerva, 36, 203-208.

Fischer, M.M., \& Varga, A. (2003), "Spatial knowledge spillovers and university research: Evidence from Austria.” Annals of Regional Science, 37 (2): 303-322.

Harhoff, D., Scherer, F.M., \& Vopel, K. (2003). "Citations, family size, opposition and the value of patent rights.” Research Policy, Vol. 32 (8), pp. 1343-1363.

Johnson, W.H.A., \& Johnston, D.A. (2004), “Organisational knowledge creating processes and the performance of university-industry collaborative R\&D projects,” International Journal of Technology Management, 27 (1), pp. 93-114.

Leydesdorff, L., \& Etzkowitz, H. (1996). "Emergence of a triple helix of university-industry-government relations" Science and Public Policy, 23, 279-286.

Meyer, M. (2000a), "Does science push technology? Patents citing scientific literature," Research Policy, 29, pp. 409434.

Meyer, M. (2000b), "Patent citations in a novel field of technology - What can they tell about interactions between emerging communities of science and technology?” Scientometrics, Vol. 48 (2), pp. 151-178.

Meyer, M., Sinilainen, T., \& Utecht, J.T. (2003), “Towards hybrid Triple Helix indicators: A study of university-related patents and a survey of academic inventors,” Scientometrics, 58 (2), pp. 321-350.

Michel, J., \& Bettels, B. (2001). "Patent citation analysis: A closer look at the basic input data from patent search reports.” Scientometrics, Vol. 51, pp. 185-201.

Monjon, S., \& Waelbroeck, P. (2003), “Assessing spillovers from universities to firms: Evidence from French firm-level data,” International Journal of Industrial Organization, 21 (9), pp. 1255-1270.

Narin, F., K.S. Hamilton, and D. Olivastro (1997), “The Increasing Linkage Between US Technology and Science”, Research Policy, 26, pp. 317 - 330

Niosi, J., \& Bas, T.G. (2001), "The competencies of regions - Canada's clusters in biotechnology.” Small Business Economics, 17 (1-2): 31-42.

Pavitt K. (1997) Do patents reflect the useful research output of universities? SPRU Electronic Working Papers Series, 6, November 1997.

Porter, M., (1995). The Competitive Advantage of Nations. The Free Press, New York.

Reitzig, M. (2004). "Improving patent valuations for management purposes - validating new indicators by analyzing application rationales.” Research Policy, 33, pp. 939-957.

Schmoch, U. (1997), "Indicators and the relations between Science and Technology”, Scientometrics, No 38, pp. 103116

Steinmueller, W.E. (1994). Basic research and industrial innovation, in: Dodgson, M., Rothwell, R. (Eds.), The Handbook of Industrial Innovation. Edward Elgar, Aldershot, pp. 54-66.

Tijssen, R.J.W., R.K. Buter and Th.N. Van Leeuwen (2000), “Technological relevance of science: validation and analysis of citation linkages between patents and research papers”, Scientometrics, 47, pp. 389-412 
Tijssen, R.J.W. (2001). "Global and domestic utilization of industrial relevant science: patent citation analysis of science-technology interactions and knowledge flows,” Research Policy, 30, 35-54.

Tijssen, R.J.W. (2002). "Science dependence of technologies: Evidence from inventors and their inventions," Research Policy, 31 (4), 509-526.

Tijssen, R.J.W. (2004). "Is the commercialisation of scientific research affecting the production of public knowledge? Global trends in the output of corporate research articles,” Research Policy, 33(5), 709-733.

Van Looy, B., Zimmermann, E., Veugelers, R., Verbeek, A., Mello, J., \& Debackere, K. (2003), "Do sciencetechnology interactions pay off when developing technology? An exploratory investigation of 10 science-intensive technology domains”, Scientometrics, 57 (3), pp. 355-367 2003.

Van Looy B., Magerman T. \& Debackere K. (forthcoming). Developing technology in the vicinity of science. An examination of the relationship between science intensity (of patents) and technological productivity within the field of biotechnology. DTEW Working Paper.

Varga, A. (1998), “University Research and Regional Innovation,” Dordrecht: Kluwer Academic Publishers.

Verbeek, A., Debackere, K., Luwel, M., Andries, P., Zimmermann, E., Deleus, F. (2002). "Linking Science to technology: Using bibliographic references in patents to build linkage schemes”, Scientometrics, Vol. 54, No. 1-2. 